\title{
Study Day of Clinical Events
}

National Cancer Institute

\section{Source}

National Cancer Institute. Study Day of Clinical Events. NCI Thesaurus. Code C87845.

The day that a clinical event occurs. 